\title{
A inserção das mulheres na ciência: narrativas de mulheres cientistas sobre a escolha profissional
}

\author{
Fabiane Ferreira da Silva \\ Universidade Federal do Pampa \\ Paula Regina Costa Ribeiro \\ Universidade Federal do Rio Grande
}

\section{Resumo}

0 artigo discute a inserção das mulheres na ciência a partir da análise de entrevistas semiestruturadas realizadas com mulheres cientistas atuantes em universidades federais e numa instituição de pesquisa do Rio Grande do Sul. No artigo, analisamos as justificativas para a escolha profissional, enfatizando as motivações, as pessoas marcantes e os acontecimentos que possibilitaram essa decisão. Procuramos compreender como se dá a inserção das mulheres na ciência, construída sobre pilares androcêntricos e sexistas. Na análise, problematizamos os discursos e práticas sociais que estiveram/estão implicados na constituição das entrevistadas, ensinando-lhes modos de ser e de agir como mulheres e de pensar e atuar com relação à ciência.

Palavras-chave: Ciência. Mulheres. Gênero. Escolha profissional. Narrativas. 


\section{The integration of women in science: scientist women discourses about their career choice}

This paper discusses the integration of women in science, based on the analysis of semi-structured interviews conducted with scientist women working in federal universities and in a research institute in the state of Rio Grande do Sul. In the article, we analyze the reasons for choosing the scientific career, emphasizing the motivations, remarkable people and events that enabled this decision making. We seek to understand how women become included in the scientific milieu, built on androcentric and sexist pillars. In the analysis, we question the discourses and social practices that were and still are entailed by the respondents' self-constitution, which teaches them ways of being and acting as women, and thinking and acting in relation to science.

Keywords: Science. Women. Gender. Career choice. Discourses.

\section{La inserción de las mujeres en la ciencia: narrativas de mujeres científicas sobre la selección profesional}

Este artículo discute la inserción de las mujeres en la ciencia desde el análisis de entrevistas semiestructuradas realizadas con mujeres científicas actuantes en universidades federales y en una institución de investigación de Rio Grande do Sul. En el artículo, analizamos las justificativas para la selección profesional, enfatizando las motivaciones, las personas marcantes y los hechos que posibilitaron esa decisión. Buscamos comprender cómo ocurre la inserción de las mujeres en la Ciencia, construida sobre pilares androcéntricos y sexistas. En el análisis, problematizamos los discursos y prácticas sociales que estuvieron/están arraigados a la formación de las entrevistadas, enseñándoles modos de ser y proceder como mujeres y de pensar y actuar con relación a la ciencia.

Palabras clave: Ciencia. Mujeres. Género. Selección profesional. Narrativas. 


\section{Palavras introdutórias}

Ao longo dos séculos, as mulheres estiveram "ausentes" do mundo da ciência. Isso não significa dizer que as mulheres não participaram da produção do conhecimento. Nos anos iniciais da Revolução Científica, muitas mulheres envolveram-se com atividades científicas, tal como observando os céus através de telescópios, olhando através de microscópios, analisando insetos ou outros animais, juntamente com seus pais, irmãos e maridos cientistas (Schiebinger, 2001). As mulheres também produziram um grande conhecimento sobre o uso de plantas e ervas medicinais utilizadas na preparação de remédios e cosméticos, além de serem responsáveis pelo acompanhamento de partos e nascimentos (Brenes, 1991; Schiebinger, 2001; Tosi, 1998).

Entretanto, a progressiva institucionalização e profissionalização da ciência, com a emergência de instituições e a determinação de normas e métodos, bem como a privatização da família restringiram a inserção e a participação das mulheres na ciência (Schiebinger, 2001). Por muito tempo, com algumas exceções, as mulheres não puderam desenvolver pesquisas nem mesmo como auxiliares, já que até recentemente eram impedidas de frequentar as instituições de ensino, pois a elas cabia assumir o cuidado da casa, dos filhos e do marido. Conforme salienta Schiebinger (2001), embora as universidades tenham sido criadas no século XII, só passaram a admitir efetivamente as mulheres em seus quadros de discentes e docentes no final do século XIX e início do século XX. Assim, a ciência se estruturou em bases quase que exclusivamente masculinas, por meio de discursos e práticas nada neutros, que excluíram e invisibilizaram as mulheres nesse contexto. Nessa perspectiva, vale lembrar que a crítica feminista à ciência já evidenciou e denunciou a exclusão e a invisibilidade das mulheres na produção e na estrutura do conhecimento, mostrando que durante a maior parte da história o sujeito do conhecimento foi o homem branco, ocidental, de classe média. Além disso, no caminho da crítica às ciências, as feministas avançaram para a denúncia do androcentrismo presente na seleção e organização dos objetos, no conteúdo das afirmações científicas, nas práticas e objetivos do processo usual de produção do conhecimento (Harding, 1993).

No contexto desta discussão, entendemos a ciência como uma construção social, cultural e histórica, implicada em fatores econômicos e políticos em meio a relações de poder. Não se trata de pensar em "influências" sobre a atividade científica que acabariam direcionando a produção do conhecimento, mas de compreender que as atividades de produzir e fazer circular o conhecimento científico estão conectadas às questões sociais, econômicas e políticas (Wortmann; Veiga-Neto, 2001). Tais entendimentos pressupõem a contingência do conhecimento científico, uma vez que a ciência 
não pode ser compreendida como um conjunto de conhecimentos em si, desconectados das instâncias em que foram produzidos. Nessa perspectiva, Haraway (1995) propõe o desenvolvimento de "saberes localizados" e "corporificados", na direção de compreender a ciência como uma construção contingente e parcial, em oposição aos saberes universais e totalizantes. Desse modo, a ciência se constituirá pelas interações entre os diferentes pontos de vista de "sujeitos múltiplos" que são responsáveis por tudo aquilo que produzem. A ciência não está fora do sujeito, mas localizada num tempo e num espaço determinados pelo gênero, etnia/raça, classe social, cultura.

Assim, a crítica feminista à ciência instrumentada pela perspectiva de gênero - e no entendimento de que o conhecimento científico é construído por seu contexto social e cultural - considera não só a discriminação e sub-representação das mulheres na ciência, que resultaram na predominância masculina entre cientistas, principalmente em determinadas áreas da ciência, mas também o predomínio de um viés androcêntrico nas atividades científicas que caracterizam os próprios fundamentos da ciência moderna. Sem dúvida a crítica feminista à ciência provocou mudanças, ampliando as formas de pensar e produzir o conhecimento científico, mas, sobretudo, contribuiu para a inserção das mulheres no mundo da ciência. Atualmente, é possível perceber o número significativo de mulheres em muitas universidades do país, entre discentes e docentes, e em diversas instituições, desenvolvendo pesquisas. Contudo, apesar da crescente presença feminina no mundo da ciência, ainda se evidencia que essa participação vem ocorrendo de modo dicotomizado ou ainda está aquém da presença masculina em determinadas áreas. Tais aspectos nos movem na direção de investigar a inserção e participação das mulheres na ciência, tomando como referência algumas áreas do conhecimento. Para tanto, nos valemos da metodologia da investigação narrativa a partir dos pressupostos de Larrosa $(1996,2004)$ e Connelly e Clandinin (1995), que discutem a narrativa como formações discursivas por meio das quais os sujeitos vão dando sentido aos fatos e aos acontecimentos narrados. Além disso, conforme destaca Larrosa (1996), é no processo narrativo que os sujeitos passam a construir a sua história, a dar sentido a quem são e a quem são os outros, constituindo assim suas identidades.

Partindo do pressuposto de que a investigação narrativa permite a utilização de diversos instrumentos para produção dos "dados" narrativos, optamos pela realização de entrevistas semiestruturadas com seis mulheres cientistas atuantes em universidades públicas e numa instituição de pesquisa do Rio Grande do Sul, sendo uma da área da farmácia, duas das ciências biológicas, duas da física e a outra da engenharia de computação. Convém enfatizar que a opção por essas áreas não significa um recorte convencional ou estreito sobre a ciência, uma vez que a ciência compreende várias áreas do conhecimento. Por um lado, a escolha pela física e engenharia de computação 
justifica-se em função da baixa participação das mulheres nessas áreas (Felício, 2010). Por outro, a escolha pela farmácia e ciências biológicas nos possibilita outro olhar relativo à participação das mulheres na ciência, já que são áreas nas quais a presença das mulheres é expressiva (Brasil, 2012). Além disso, a escolha das participantes da pesquisa obedeceu a alguns critérios, tais como: ter mais de 15 anos de atuação profissional, desenvolver atividades de pesquisa, possuir projetos financiados por agências de fomento à pesquisa científica e tecnológica, atuar na graduação e na pós-graduação.

Assim, as participantes da pesquisa são cientistas que produzem conhecimentos em diferentes áreas da ciência, as quais se encontram em diferentes estágios na carreira, sendo uma delas pesquisadora aposentada. Das seis cientistas, duas possuem bolsa de Produtividade em Pesquisa e uma possui bolsa de Produtividade em Desenvolvimento Tecnológico e Extensão Inovadora. São mulheres cientistas de diferentes idades (na faixa etária de 40 a 75 anos), que ocupam posições de relevo na carreira, que encabeçaram linhas de pesquisa, com vasta experiência e trajetória. No artigo, analisamos as narrativas dessas mulheres sobre suas escolhas profissionais, buscando enfatizar discursos, experiências, acontecimentos e pessoas que motivaram e influenciaram as participantes da pesquisa a ingressarem na ciência. As narrativas aqui partilhadas refletem sonhos, desejos, perspectivas, incentivos, motivações, decisões, lugares, tempos, a presença da família, professores e professoras que marcaram a vida das entrevistadas e estiveram implicados na escolha por determinadas áreas da ciência.

\section{Tempos, memórias e experiências: compondo narrativas sobre a escolha profissional}

A recordação não é apenas a presença do passado. Não é uma pista, ou um rastro, que podemos olhar e ordenar como se observa e se ordena um álbum de fotos. A recordação implica imaginação e composição, implica um certo sentido do que somos, implica habilidade narrativa (Larrosa, 2002, p. 68).

Trilhar as histórias vividas por um grupo de mulheres cientistas sobre a identificação com a área de atuação e a escolha profissional tem-nos permitido discutir e compreender questões relacionadas à inserção e à participação das mulheres em determinadas áreas da ciência, bem como problematizar determinados discursos e práticas sociais implicados nos processos de subjetivação e (re)construção das identidades dessas mulheres. Nesse sentido, analisar as narrativas que foram produzidas implicou em um grande desafio na direção de conhecer os discursos e as práticas sociais que constituíram e constituem os sujeitos desta pesquisa. Sem pretender traçar 
generalizações, entendendo que os percursos vividos são individuais, embora também coletivos, procuramos encontrar pontos de encontro nas histórias de vida das participantes, na direção de tecer uma rede discursiva sobre os acontecimentos sociais, culturais, históricos e econômicos que se constituíram em condições de possibilidade para o ingresso delas na ciência. Embora tenhamos construído certa linearidade na análise das narrativas sobre as escolhas profissionais, entendemos que as narrativas produzidas pelas participantes não constituem textos de acontecimentos lineares e ordenados temporalmente, mas sim num processo descontínuo de ir e vir nos fatos, acontecimentos e experiências, individuais e coletivas, que marcaram suas vidas e as transformaram em sujeitos. Conforme destaca Larrosa (2002, p. 69), “o narrador pode oferecer sua própria continuidade temporal, sua própria identidade e permanência no tempo [...] na mesma operação na qual constrói a temporalidade de sua história". A partir das contribuições de Larrosa $(1996,2002)$, tomamos a narrativa como uma modalidade discursiva na qual os sujeitos constroem e transformam a experiência de si. Para o autor,

0 que somos ou, melhor ainda, o sentido de quem somos, depende das histórias que contamos e das que contamos a nós mesmos. Em particular, das construções narrativas nas quais cada um de nós é, ao mesmo tempo, o autor, o narrador e o personagem principal. Por outro lado, essas histórias estão construídas em relação às histórias que escutamos, que lemos e que, de alguma maneira, nos dizem respeito na medida em que estamos compelidos a produzir nossa história em relação a elas. Por último, essas histórias pessoais que nos constituem estão produzidas e mediadas no interior de práticas sociais mais ou menos institucionalizadas (Larrosa, 2002, p. 48-49).

Nos processos narrativos é que os sujeitos estabelecem suas posições de sujeito, constroem suas identidades, uma vez que "é contando histórias, nossas próprias histórias, o que nos acontece e o sentido que damos ao que nos acontece, que nos damos a nós próprios uma identidade no tempo" (Larrosa, 2002, p. 69). De acordo com Larrosa (1996), a identidade não é algo que progressivamente encontramos ou descobrimos, mas sim algo que inventamos e modificamos na gigantesca e polifônica conversação de narrativas que é a vida e que inclui as pessoas com quem nos relacionamos. Portanto, a identidade não é inata, geneticamente predeterminada, fixa ou permanente, mas é construída, fabricada, negociada, contestada em meio aos processos discursivos e às práticas sociais. Nessa direção, Hall (2005, p. 13) discute a identidade como "uma 'celebração móvel': formada e transformada continuamente em relação às formas pelas quais somos representados ou interpelados nos sistemas culturais que nos rodeiam". Para o autor, 
0 sujeito assume identidades diferentes em diferentes momentos, identidades que não são unificadas ao redor de um "eu" coerente. [...] A identidade plenamente unificada, completa, segura e coerente é uma fantasia. Ao invés disso, à medida em que os sistemas de significação e representação cultural se multiplicam, somos confrontados por uma multiplicidade desconcertante e cambiante de identidades possíveis, com cada uma das quais poderíamos nos identificar - ao menos temporariamente (Hall, 2005, p. 13).

Assim, é nas práticas sociais, atravessadas por relações de poder e saber, que as participantes desta pesquisa constroem e modificam tanto a experiência de si quanto do mundo em que estão inseridas. É a partir das narrações dessas mulheres cientistas que buscamos construir uma rede de significados sobre a inserção delas na ciência. As narrativas apresentadas a seguir trazem aspectos referentes aos processos de escolha do curso de graduação das mulheres participantes desta pesquisa. Essas narrativas foram analisadas numa perspectiva foucaultiana, uma vez que recusamos o entendimento de sentido "oculto" no discurso, ou seja, não há nada por trás do discurso que precise ser revelado. Para proceder à análise das narrativas, examinamos o que foi dito pelas cientistas, considerando que as palavras também são construídas sempre em relações de poder, ou seja, a partir dos mecanismos de interdição sociais (Foucault, 2004).

Nas justificativas para a escolha da profissão e o ingresso na universidade, foram surgindo sonhos, desejos, sentimentos, pessoas, brincadeiras e lugares que marcaram suas histórias e as constituíram/constituem mulheres e cientistas. Reportemo-nos inicialmente às vivências da infância e adolescência, muitas delas relacionadas com as experiências escolares, como o período narrado pela maioria das cientistas para justificar a escolha profissional. As cientistas da área da física e da engenharia destacaram a identificação com as ciências exatas, a facilidade com física e matemática, transformada em gosto por essas áreas, bem como a curiosidade e a criatividade como fatores decisivos na escolha da profissão:

Eu sempre gostei muito de ciências exatas, eu tinha muita facilidade com matemática e física. Por outro lado, eu sempre fui muito curiosa, sempre inventava coisas. Lá pela sexta ou sétima série eu dizia que eu queria ser cientista, e ser cientista pra mim era trabalhar com química em laboratório. Essa era a visão que eu tinha. Então, eu queria ser cientista e queria trabalhar com vidrinhos e coisas. Tinha aqueles kits de laboratório, sabe aqueles kits de química? Adorava brincar com aquilo, vivia no quintal brincando com coisas assim de inventar. Então, o inventar coisas misturado com a facilidade de matemática e física fizeram com que eu achasse que seria legal pra mim eu fazer alguma coisa em termos de exatas. Até me lembro de conversar com o meu pai e ele dizer 
assim: “É... tu pode ser professora de matemática, tu pode ser professora de física, tu pode ser engenheira; engenheira talvez seja melhor, porque tem aquela coisa social." Aí, no final do terceiro ano do segundo grau, optei por fazer engenharia civil (Lili). ${ }^{1}$

No primeiro e segundo grau eu sempre tive muita facilidade nas exatas, adorava matemática, e quando eu tava no segundo grau eu estava naquela: o que eu vou fazer de vestibular? Aí eu queria fazer tudo, tanto que eu fiz vestibular pra física e pra jornalismo, imagina! Queria fazer arquitetura também, pensei em fazer engenharia. As coisas mais nas exatas, por conta da minha facilidade na matemática. Eu não queria fazer matemática propriamente dita como bacharel pesquisador. Bom... óbvio, eu não queria ser professora. Eu queria ser cientista ou ser uma profissional, não uma professora. Então, fazer licenciatura, isso eu tinha bem claro que eu não queria. Eu não queria fazer bacharelado em matemática porque eu achava muito abstrato. Eu estava fazendo cursinho, e no cursinho eu tive um professor de física que foi o primeiro professor que despertou o que era física. Não era aquela aula de física do segundo grau que os professores são sempre muito... não sei, os meus professores eram muito aborrecidos, não transmitiam muita emoção pela disciplina, e esse professor transmitiu. Então eu achei que fazer física era uma boa ideia. Então eu resolvi fazer graduação em física, fiz vestibular e entrei (Sianiak).

Sempre fui uma aluna com boas notas. Durante o segundo grau trabalhava à noite no laboratório do colégio, montando experimentos de química, física e biologia. Os meus pais sempre estimulavam os meus estudos. Tive um professor de física muito bom e um pai que era eletricista e consertava tudo em casa, e que sempre me chamava para dar uma mão. Pensei em diversas áreas: escrever, fazer teatro, ser embaixadora... No terceiro ano decidi ser física, pois identificava aí uma profissão onde eu poderia resolver problemas e criar (Salamandra).

Essas narrativas sobre os motivos que levaram à escolha da profissão tornam possível perceber que as opções pelos cursos universitários, (re)significadas nessas falas, foram atravessadas por determinados discursos, carregados de saberes e poderes, que produziram efeitos nas escolhas profissionais das entrevistadas. Os argumentos que emergem das narrativas que justificam a escolha pela física e engenharia estão relacionados ao entendimento de que, para ingressar nessas áreas, é necessário apre-

1. A fim de garantir o anonimato, as participantes escolheram nomes fictícios com os quais gostariam de ser identificadas na pesquisa. 
sentar determinados conhecimentos e habilidades condizentes com o perfil de alunolal que cada curso espera.

Desse modo, essas narrativas nos possibilitam pensar e discutir as representações dos cursos de física e engenharia presentes na mídia, nos livros, na escola, na família, entre outros espaços, que apresentam essas áreas do conhecimento como difíceis, complexas, que exigem dolal aluno(a) muitas horas de estudo e principalmente domínio em física e matemática. Nesse sentido, é importante destacar os efeitos dos sistemas de representação na constituição dos sujeitos, uma vez que essas e outras representações, ao acessarem os sujeitos, produzem as identidades e as diferenças, posicionando-os (Woodward, 2005). Tornamo-nos sujeitos a partir das representações que transitam no contexto social; elas significam a nossa experiência, aquilo que somos ou o que podemos ser, aquilo que gostamos ou que não gostamos, aquilo que queremos e desejamos. Cabe destacar que, quando falamos em representação, não estamos tratando de um mero espelho do real ou reflexo de uma realidade anterior e independente do discurso que a nomeia, mas de uma representação produzida pela linguagem que, atravessada por relações de poder/saber, carrega valores, crenças, concepções de mundo de quem está representando (Silva, 2005). Em outras palavras, isso significa que a física e a engenharia, ao serem descritas, por exemplo, pelos discursos veiculados pela mídia, família e escola, produzem significados sobre esses cursos. Nessa perspectiva, as formas como determinadas profissões foram/são narradas produziram/produzem certos significados com os quais as participantes desta pesquisa aprenderam/ aprendem a se identificar. Alguns dos elementos que emergem das narrativas apresentadas criam condições para problematizarmos os significados atribuídos a determinadas profissões, especialmente o status social que algumas profissões possuem em contraponto à desvalorização da docência, tão em voga na nossa sociedade.

A ciência, constituída como um espaço legitimador de conhecimento, instituiu o que é um(a) cientista, quem pode ser e nomear-se cientista, afinal "não são todos que podem falar da ciência, fazer ciência e sentir-se cientista. Esta é uma classe especializada e restrita" (Henning, 2008, p. 87). Vale lembrar que a representação de cientista ainda dominante, colocada em circulação em diversas instâncias sociais - família, mídia, escola, universidade -, e em artefatos culturais - programas de TV, novelas, revistas, jornais, anúncios publicitários, livros, por exemplo -, é a imagem de uma pessoa vestida de jaleco branco, que tem o espaço do laboratório como locus de investigação e produção do conhecimento científico. Relacionado a essa representação está o entendimento de que olal cientista é uma pessoa inteligente, dedicada, estudiosa, criativa, que busca inventar "coisas" e solucionar problemas. Essa representação de cientista, veiculada nas histórias em quadrinhos, nos desenhos animados, nos comerciais, nos brinquedos, 
entre outros artefatos culturais, certamente fez e ainda faz parte da vida de muitas crianças, jovens e adultos. Para ilustrar, destacamos o professor Pardal, um galo antropomorfo, personagem dos quadrinhos da Disney. Embora tenha sido criado por Carl Barks em 1952, o personagem ainda circula na mídia televisiva. Sempre ao lado de seu pequeno companheiro Lampadinha lum pequeno androide com uma lâmpada no lugar da cabeçal, é considerado um inventor genial e maluco, que vive criando aparelhos e engenhocas. Também lembramos o Franjinha, personagem da Turma da Mônica criado por Maurício de Souza em 1959. 0 personagem é um menino inteligente e curioso, que está sempre criando coisas em seu "laboratório", num galpãozinho no fundo do quintal, para ajudar seus amigos. Atualmente são outros os personagens que povoam os desenhos animados, a exemplo do Sid, um menino cientista; do Pinky e do Cérebro, dois ratos brancos típicos de laboratório; do Dexter, um menino considerado gênio, que possui um imenso laboratório secreto conectado ao seu quarto; do Jimmy Neutron, outro menino gênio. Ainda cabe destacar que, não por coincidência, todos esses personagens estão relacionados ao masculino.

Não é nosso propósito realizar uma análise aprofundada desses personagens, uma vez que teríamos que discutir os interesses sociais, políticos e econômicos da produção dos mesmos. No entanto, especialmente a fala de Lili, quando argumentou que sempre foi muito curiosa, que vivia inventando coisas, que queria ser cientista e que ser cientista era trabalhar com química no laboratório, apresenta elementos relacionados com a tradicional representação de cientista, elementos que nos possibilitam problematizar os efeitos dessa representação na constituição dos sujeitos. Nesse sentido, entendemos que as imagens de cientistas que circulam no contexto social desenvolvem determinadas "pedagogias", produzindo significados, veiculando saberes, transmitindo valores que, ao interpelarem os sujeitos, produzem o desejo de querer ser de determinada maneira, valorizar certas características e habilidades, reconhecer-se e pensar-se de determinado jeito.

Com a consolidação da ciência como a "grande narrativa" da Modernidade, consolidase também a representação de cientista como um(a) profissional prestigiadola) e legitimado(a) pela própria sociedade, que passa a conferir-lhe status e autoridade intelectual na compreensão e definição da realidade/natureza em benefício da humanidade, tendo o discurso científico como base para a produção do conhecimento. Assim, o(a) cientista passa a ser a voz da ciência, a pessoa autorizada a construir a ciência, aquele ou aquela que possui as características e habilidades necessárias para tanto. Portanto, ocupar a posição de cientista é ocupar um lugar privilegiado e reconhecido social e financeiramente, em meio às diferentes possibilidades profissionais. Tais entendimentos podem ser percebidos na fala de Lili, ao destacar os incentivos do pai 
para que ela fosse engenheira: “É... tu pode ser professora de matemática, tu pode ser professora de física, tu pode ser engenheira; engenheira talvez seja melhor, porque tem aquela coisa social."

Sobre os incentivos para a escolha da profissão, queremos chamar a atenção para a presença marcante do pai de Lili na sua escolha profissional. Ao longo da entrevista, Lili enfatizou o incentivo do seu pai para que ela fizesse engenharia, que no nosso entender se dá em função tanto do desejo de querer ser engenheiro e não ter tido a possibilidade de estudar, como também do status profissional que um curso de engenharia significava.

Meu pai foi fiscal da Receita. Ele começou a trabalhar muito cedo, na época não precisava de curso superior. Ele não pôde fazer curso superior, mas ele é o cara mais engenheiro que eu conheci, mesmo sem ser engenheiro. E aquela coisa de filha mais velha, somos duas irmãs, então aquela coisa meio que de projetarem. Ele projetou mais ou menos em mim, talvez, o que ele quisesse ser. Eu acho que teve um pouco de projeção, ele sempre quis ser [engenheiro], estudar engenharia e não teve possibilidade (Lili).

Além do fato de o pai de Lili não ter tido filhos e ela ser a filha mais velha, o que pode ter contribuído para que ele a incentivasse a fazer um curso de engenharia, projetando nela a realização do desejo de ser engenheiro, é importante lembrar que a engenharia tem reconhecido prestígio nos rumos profissionais, em função da possibilidade de inserção num mercado de trabalho amplo e diversificado. Nessa perspectiva, é importante enfatizar o contexto econômico, político e social da metade da década de 80, período em que Lili ingressou na universidade. Nesse contexto, o Brasil vivia um período de estagnação econômica, marcado pela inflação e pelo desemprego, decorrente, entre outros fatores, da forte retração da produção industrial. Entretanto, a engenharia elétrica passava por um momento de expansão no país em função do crescimento da informática nacional, que colocava o Brasil na sexta posição do mercado mundial da informática. Tais questões emergem na narrativa de Lili como justificativa para a escolha pela engenharia elétrica:

$\mathrm{Na}$ época tinha reserva de mercado pra computação, foi bem no início que começaram a vender esses computadores, todos eles eram fabricados no Brasil. E era um curso que, na época, as pessoas saíam empregadas por essas empresas de fabricação de computadores. Então, tinha um valor agregado à engenharia elétrica que era superalto, que hoje já não é tanto, virou um pouco pro lado da computação essa parte. Então eu entrei na engenharia elétrica na época de reserva de mercado de todas as empresas 
que construíam computadores. Na época era a EDISA, a DIGICOM, a COBRA, tinham várias sendo criadas na universidade. Aquilo lá fervilhava por conta de toda a nacionalização da eletrônica, porque tudo era feito no Brasil (Lili).

Assim, de um modo geral, o contexto histórico da engenharia em meados dos anos 80, que passava por modificações no nível de prestígio e status atribuído aos(às) profissionais, somado ao incentivo do pai para que Lili fosse engenheira e não professora, constituem as condições de possibilidade para a inserção dela na engenharia. Já Sianiak foi enfática, ao argumentar que não queria ser professora. Nas palavras dela: "Eu queria ser cientista ou ser um profissional, não uma professora. Então, fazer licenciatura, isso eu tinha bem claro que eu não queria.".

Não temos a pretensão de examinar com profundidade as questões que envolvem a profissão de docente, fato que exigiria reflexões sobre os significados da educação na sociedade contemporânea, bem como uma discussão sobre as demandas vinculadas às atividades docentes. Entretanto, não há como negar, conforme destaca Guimarães (2006, p. 45), que a profissão de docente apresenta algumas marcas históricas: desvalorização, desqualificação e proletarização do professor, "feminização" do magistério, caráter vocacional, que constituem e contribuem para "manter a identidade da profissão docente como um 'que fazer' de baixa aspiração profissional a ser desenvolvido por pessoas cordatas e generosas que, mesmo 'reconhecidamente' merecedoras, contentamse com pouco (baixo salário, condições de trabalho modestas etc.)".

Ainda sobre a profissão de docente, especialmente a narrativa de Sianiak, quando disse que os seus professores eram tão aborrecidos, levou-nos a pensar no texto "Por que somos tão tristes?", de Corazza (2004, p. 52), no qual ela problematiza as tristezas do exercício da profissão de docente, uma vez que, "ao educar, predominam paixões tristes, forças reativas, ressentimentos e até mesmo infelicidades" - tristezas que, para a autora, há quase um século criam uma imagem pobre e medíocre dolal professor(a), que fazem com que se repitam os mesmos atos, se exijam os mesmos conteúdos, se perguntem as mesmas perguntas, se tenha menos amor à profissão. Entretanto, “não é preciso ser triste para ser professor, mesmo se o que ocasiona nossa tristeza for abominável" (Corazza, 2004, p. 53). Existem aqueles(as) que marcam os(as) alunos(as) pela paixão de ensinar, pela vibração com que explicam seus conteúdos, por acreditarem que é possível fazer a diferença na educação. Estes foram mencionados nas narrativas das entrevistadas como motivadores para a escolha profissional. Para ilustrar, retomamos as seguintes falas: "tive um professor de física muito bom" (Salamandra); "no cursinho eu tive um professor de física que foi o primeiro professor que despertou o que era física. Não era aquela aula de física do segundo grau que os 
professores são sempre muito... não sei, os meus professores eram muito aborrecidos, não transmitiam muita emoção pela disciplina e esse professor transmitiu. Então eu achei que fazer física era uma boa ideia" (Sianiak).

Os efeitos dos(as) professores(as) na vida das entrevistadas, no que diz respeito à identificação com a área do conhecimento e à escolha profissional, também podem ser percebidos na narrativa que se segue.

$\mathrm{Na}$ época, quando eu fazia o segundo grau, eu sempre gostei dessa parte de biologia, eu acho que isso foi muito da responsabilidade de bons professores que eu tive em ciências. Sempre em biologia eu me identificava com o professor, mas sem dúvida um dos professores que mais contribuiu pra cada vez mais eu gostar da biologia foi o professor [nome]. E ele me deu aula no [nome da escola], e me apresentou uma biologia lindíssima. Eu tenho o meu caderno guardado até hoje, aquilo é uma relíquia, porque ele era muito fantástico. Eu já gostava, porque eu acho que é uma coisa que já vem, eu sempre gostei dessas coisas vivas, principalmente animais. Tive a professora [nome], completamente diferente, mais teórica do que prática, mas também vibrante com o que ela fazia, e essas coisas foram me tocando bastante. E eu sempre me via como professora. Quando eu brincava, eu botava as bonequinhas sentadas no chão e eu ficava dando aula, assim o dia inteiro falando sozinha, fazia as bonecas irem no quadro, me dava o trabalho de fazer letrinhas diferentes pra mostrar que cada aluno era um [risos] (Bildi).

Além da identificação com professores e professoras de biologia, essa narrativa nos possibilita estabelecer aproximações entre as histórias de vida das entrevistadas, na direção de contrapor entendimentos sobre a perspectiva profissional. Se por um lado Sianiak enfatizou que tinha clareza de que não queria ser professora, conforme já discutimos, por outro a Bildi contou que sempre se via como professora. Ao analisarmos a narrativa da Bildi, podemos dizer que ela "exercitava" a profissão de docente nas suas brincadeiras, por meio da reprodução de experiências que vivenciava como aluna e que certamente estiveram/estão implicadas na constituição da sua identidade profissional, desmistificando o entendimento de que a identidade profissional é construída apenas nos cursos de formação. Para pensar sobre essas questões, encontramos apoio nas discussões feitas por Arroyo (2011), quando destaca que a imagem de professor(a) que os profissionais da educação carregam le aqui poderíamos acrescentar não apenas os profissionais da educação, como também os profissionais de outras áreas), não são inventadas por eles(as), nem aprendidas apenas nos cursos de formação, mas são imagens sociais que definem os papéis culturais, suas formas de se relacionar com as pessoas, aprendidos em suas experiências cotidianas, ou seja, 
no convívio e no cuidado com irmãos e irmãs, nas atividades e vivências escolares, nas brincadeiras de crianças, entre outras.

As marcas de determinadas brincadeiras e brinquedos de criança também emergiram na narrativa de outras entrevistadas para justificar a escolha da profissão. Para ilustrar, apresentamos a narrativa de Mariana:

Eu desde pequena já gostava muito dessa coisa de química e tinha aqueles laboratórios de química pra criança, sempre gostei muito. Aí, depois, numa certa época da minha vida eu fiquei em dúvida se fazia medicina ou farmácia [...]. E aí, na dúvida, eu fui fazer farmácia. Na época que eu fiz o segundo grau. Era uma época que tinha os pseudoprofissionalizantes, e eu peguei então um tipo técnico de laboratório (Mariana).

Essa narrativa nos possibilita discutir os brinquedos/brincadeiras como "artefatos da cultural" implicados na constituição dos processos identitários dos sujeitos. Para Bujes,

[...] os brinquedos, enquanto elementos da vida social que se configuram com determinados sentidos para as crianças, oferecem oportunidades para que elas percebam a si e aos outros como sujeitos que fazem parte do mundo social, e acabam por se constituir em estratégias através das quais os diferentes grupos sociais usam a representação para fixar a sua identidade e dos outros (Bujes, 2000, p. 227).

Nessa perspectiva, é preciso enfatizar que a produção de qualquer brinquedo está intimamente articulada com as dimensões históricas, culturais, econômicas e políticas. 0 brinquedo ao qual Mariana se refere, que também pode ser percebido na fala de Lili, chama-se 0 Pequeno Químico, brinquedo muito popular das décadas de 60 e 70, que consistia em um minilaboratório, contendo um conjunto de recipientes de plástico e algumas soluções e pigmentos. É interessante destacar que a emergência desse brinquedo no Brasil se dá no contexto histórico que se segue ao lançamento do satélite Sputnik, pelos russos, acontecimento que provocou mudanças em diversas instâncias sociais, entre elas a escola.

Não pretendemos, nos limites deste artigo, discutir a repercussão daquele evento para a área da educação, especialmente para os currículos de ciências, no entanto cabe mencionar, embora brevemente, que naquele período os(as) cientistas ocupavam uma posição de prestígio e viam na educação uma importante área potencial de investimentos. Nesse contexto, surgiram diversos projetos curriculares organizados principalmente pelos Estados Unidos, traduzidos e divulgados no Brasil, com o objetivo de 
reformular o ensino de ciências em função do expressivo desenvolvimento da ciência e da tecnologia, a fim de formar cientistas e preparar olal cidadão para conviver com a produção científica e tecnológica (Galiazzi et al, 2001; Krasilchik, 2006). Para tanto, era preciso incorporar a vivência do método científico, isto é, "aprender a observar e registrar dados, aprender a pensar de forma científica, desenvolver habilidades e técnicas no manuseio do instrumental do laboratório. Era preciso ser treinado para resolver problemas" (Galiazzi et al, 2001, p. 253). Considerando essas questões, o que procuramos mostrar é que os efeitos da ciência não se restringiram/restringem apenas às mudanças curriculares. A ciência, constituída como um "consistente regime de verdade" (Henning, 2008, p. 24), produz efeitos nas nossas vidas, nas formas como nos percebemos e como nos relacionamos com as pessoas, nos artefatos culturais que consumimos, nas atividades que praticamos e aprendemos a gostar, atuando como um importante sistema de governo dos nossos corpos e das nossas vidas.

Dando continuidade à análise das narrativas, transcrevem-se as palavras de Carolina, cientista que justificou a sua escolha pela área da biologia em função da sua vocação para algo que tivesse a ver com a natureza. Nas palavras dela:

Eu tinha uma vocação pra alguma coisa que tivesse que ver com a natureza, e quando eu fui fazer vestibular... eu fiz o segundo grau no [nome da escola], que era a melhor coisa pra preparar para uma universidade naquela ocasião. Entrei na faculdade em 57 e me formei em 60. Eu estava fazendo [nome da escola] e trabalhava em banco. Bom... aí eu não tive muito tempo, eu não fiz cursinho. Eu tinha certeza que eu queria fazer faculdade. E eu fiquei entre a agronomia e a biologia. Só que para a agronomia eu teria que fazer prova de física e química, e eu tinha ficado em segunda época de matemática e física. Eu enfrentei a segunda época [nome da escola] junto com o vestibular e eu sabia que eu não era boa nisso aí. Eu disse assim: Vou fazer para História Natural, porque eu acho que eu tenho mais chance de passar (Carolina).

Embora o discurso da vocação tenha emergido na narrativa da Carolina, a escolha entre a agronomia e a biologia deu-se muito mais no confronto de determinadas situações e entendimentos que se relacionam com o pouco tempo disponível para estudar para o vestibular e com a dificuldade em determinadas disciplinas que seriam exigidas, caso optasse pelo vestibular em agronomia. Novamente essa narrativa nos leva a pensar que as nossas escolhas são sempre atravessadas por determinados discursos profundamente implicados com relações de poder que, ao nos interpelar, moldam e regulam os nossos entendimentos, percepções, desejos, sentimentos, transformando-nos em sujeitos. Para finalizar a análise das narrativas sobre a escolha 
profissional, queremos destacar a narrativa de Carolina, que, ao contrário de outras cientistas, argumentou que não teve incentivos da mãe para fazer faculdade.

$\mathrm{Na}$ verdade a minha mãe não queria que eu fizesse faculdade. Quando eu estava trabalhando no banco, ela achava que o meu futuro era por ali. Ela pensava: "Os filhos têm que ter emprego, as filhas têm que casar." Bom, daí a mãe não queria, quando eu disse para ela que eu tinha que largar o banco, porque na faculdade tem aula de manhã, de tarde, de noite, e eu não pude mais acompanhar com o trabalho no banco e tive que largar o emprego. Aí eu falei para meu pai: "Eu não vou poder ganhar mais dinheiro, eu vou buscar uma bolsa, mas tu vais ter que me segurar." Ele disse: "Eu vou te segurar, podes ir em frente com a faculdade." E a mãe não, a mãe teve uma crise séria. Depois, como ela não estava aceitando aquilo, eu disse: "Pai, eu vou ter que sair de casa, vou ter que ir para um pensionato porque a mãe não está me deixando em paz." Aí ele disse assim: "Pode ir, filha.". Quando a mãe soube que eu ia sair de casa, aí ela voltou atrás, aí ela viu que aquilo não tinha volta, e daí por diante ela sempre me apoiou e não tive mais problemas (Carolina).

Essa narrativa nos possibilita pensar na história de lutas reivindicatórias pelo acesso à educação travada por tantas mulheres e movimentos sociais, que parece estar quase esquecida diante da possibilidade de as mulheres estudarem atualmente. Dados recentes divulgados pelo INEP e pelo CNPq mostram que a representatividade feminina é superior em todos os níveis do sistema educacional. As mulheres correspondem à maioria dos estudantes que concluem o ensino fundamental e o ensino médio²; são maioria na graduação ${ }^{3}$, tanto no número de matriculados quanto no número de concluintes, e também se encontram em maior número no mestrado e no doutorado ${ }^{4}$. Entretanto, embora atualmente as mulheres estejam inseridas em todos os níveis educacionais, cabe lembrar que nem sempre foi assim.

No Brasil, o processo educacional para ambos os sexos teve início com os jesuítas, que se dedicaram à cristianização dos indígenas, à formação da classe eclesiástica e à educação dos filhos da classe dominante. Durante o período colonial, a educação feminina restringia-se à leitura, à escrita e a noções básicas de matemática suficientes

2. Sinopse da Educação Básica 2009, planilha 6.1.3 para o Ensino Fundamental e 6.1.7 para o Ensino Médio. Disponível em: <http://portal.inep.gov.br/basica-censo-escolar-sinopse-sinopse>. Acesso em: 15 out. 2011.

3. Censo Superior 2009, planilha 5.3 para matriculados e 6.3 para concluintes. Disponível em: <http://portal.inep.gov.br/ superior-censosuperior-sinopse>. Acesso em: 15 out. 2011.

4. Distribuição percentual dos estudantes por sexo segundo o nível de treinamento, 2010. Disponível em: <http://dgp. cnpq.br/censos/sumula_estatistica/2010/estudantes/estudantes.htm>. Acesso em: 15 out. 2011. 
para administrar a casa, bem como ao aprendizado das prendas domésticas, incluindo, por exemplo, o bordado e a costura. Somente em meados do século XIX é que começaram a ser criadas as primeiras instituições destinadas a educar as mulheres - as Escolas Normais -, nas quais a educação primária dava-se com forte conteúdo moral e social, dirigido ao fortalecimento do "papel" da mulher como mãe e esposa, com ênfase no aprendizado de costura, bordado e alguns conhecimentos que auxiliassem na economia doméstica; já a educação secundária ficava restrita, em grande medida, à formação de professoras para os cursos primários (Beltrão; Alves, 2009).

Nesse contexto, a educação feminina estava restrita ao ensino elementar, já que a educação superior era eminentemente masculina. As mulheres foram proibidas de ingressar nas primeiras faculdades brasileiras - Medicina, Engenharia e Direito -, estabelecidas no século XIX, e só tiveram acesso às universidades em 1879, com a Reforma Leôncio de Carvalho, que passou a permitir o ingresso de mulheres em instituições de ensino superior. 0 ingresso das mulheres nas universidades foi intensificado a partir de 1950, atrelado também à sua crescente inserção no mundo do trabalho. Entretanto, mesmo com as mudanças em diversos setores decorrentes do pós-guerra, as expectativas que a mãe de Carolina tinha para com a filha estavam relacionadas ao casamento, considerado um marco na vida das mulheres, destino "natural" para as mulheres, definidor de possibilidades e trajetórias. Desse modo, a inserção de Carolina no ensino superior se deu em meio a confrontos familiares, em processos de embates e resistências ao que a mãe esperava para ela. Tais questões nos levam a pensar que as expectativas sociais dirigidas para as mulheres na esfera privada tendem a limitar e dificultar sua inserção no ensino superior como esfera pública e masculina. A profissionalização de mulheres e homens passa por discursos diferentes. Dos homens esperase o trabalho remunerado, a fim de suprir as necessidades da família; por outro lado, das mulheres esperam-se o espaço privado, o casamento, as obrigações para com as atividades domésticas e o cuidado dos filhos.

\section{Palavras finais}

Neste texto buscamos discutir as motivações para a escolha profissional de um grupo de mulheres cientistas. Ao justificarem a escolha da profissão, elas procuraram dar significados aos aspectos que estiveram implicados na escolha profissional, que se constituíram de diferentes processos discursivos e práticas sociais, ora de identificação, ora de confronto, nas interações com pessoas da família, com antigos(as) professores(as), nas experiências escolares, na interação com determinadas produções culturais, tais como brinquedos e brincadeiras. 
Assim, a análise das narrativas evidenciou a escolha profissional das entrevistadas como uma decisão construída a partir de motivos pessoais que foram atravessados por incentivos familiares, por pessoas que se constituíram como referência, por determinadas representações da ciência e de cientista, por questões econômicas, pela possibilidade de inserção no mercado de trabalho, pelo status social de algumas profissões, entre outros aspectos, que se configuraram como condições de possibilidade para o ingresso das entrevistadas na ciência. Desse modo, chamamos a atenção para o papel de determinados artefatos culturais e instâncias sociais na constituição das participantes da pesquisa, que por meio de produção de discursos e práticas sociais ensinam maneiras de ser, pensar, agir, gostar, escolher, etc. Transitar nas narrativas das entrevistadas acerca das justificativas para a escolha profissional tem-nos possibilitado entender o sujeito como produzido nos acontecimentos que experiencia cotidianamente, como, por exemplo, nos processos de socialização, nas brincadeiras, nas relações familiares, na interação com artefatos da cultura, entre outros. São eles que nos ensinam os significados que passamos a atribuir às "coisas" à nossa volta, às pessoas e a nós mesmos. Aprendemos, por exemplo, a gostar ou não de matemática e física, a querer ser professorlal ou cientista, a interpretar as situações cotidianas, a fazer escolhas, entre outras aprendizagens.

Ao discutir a inserção e a participação das mulheres na ciência a partir das narrativas de um grupo de mulheres cientistas, não tivemos a intenção de emitir generalizações, uma vez que analisamos histórias de vidas de mulheres específicas, portanto localizadas, embora produzidas na interseção entre as histórias pessoais e a história da sociedade que as contextualiza. Queríamos conhecer as motivações para a escolha profissional das participantes da pesquisa e com isso discutir o atravessamento de alguns discursos e práticas sociais na constituição das entrevistadas, ensinando-lhes modos de ser e agir como mulheres e de pensar e atuar com relação à ciência.

Considerando as questões discutidas neste texto, queremos enfatizar que a inserção das mulheres na ciência, especialmente em determinadas áreas do conhecimento, não depende somente de características individuais das mulheres, mas sim de fatores microestruturais e macroestruturais, de acontecimentos sociais, culturais, históricos, bem como econômicos e políticos, conforme verificamos nas narrativas das entrevistas. Nesse sentido, concordamos com Schiebinger (2001, p. 37), quando argumenta que a ciência é um produto de centenas de anos de exclusão das mulheres, e que, portanto, "o processo de trazer mulheres para a ciência exigiu, e vai continuar a exigir, profundas mudanças estruturais na cultura, métodos e conteúdo da ciência”. Nas últimas décadas, verificou-se uma crescente participação das mulheres no mundo científico. No entanto, ainda é marcante a permanência das mulheres em campos do conheci- 
mento tradicionalmente ligados à identidade feminina, como Psicologia, Linguística, Nutrição, Serviço Social, Fonoaudiologia, Economia Doméstica, Enfermagem, que remetem aos "papéis" de gênero ligados à doação, ao cuidado e à maternidade (Felício, 2010). Áreas do conhecimento como Astronomia, Matemática, Engenharias, Ciência da Computação e, sobretudo, Física constituem as áreas de menor participação das mulheres (Felício, 2010).

Velho e León (1998, p. 321-322), ao questionarem essa divisão sexista na ciência, enfatizam que as áreas que têm um componente biológico forte, e também poderíamos acrescentar as humanidades, tendem a ser aquelas "para as quais as mulheres são sutilmente, ou não tão sutilmente, empurradas, seja pelo [...] processo de socialização que as [induz] a não gostar de Matemática e a acharem que devem se interessar pelos seres vivos, seja porque tais disciplinas têm menor status e/ou menor remuneração". Tais questões, no nosso entender, estão relacionadas com os "regimes de verdade" do nosso tempo, ou seja, com os discursos/representações sobre mulheres e homens que a sociedade aceita e faz funcionar como "verdadeiros", que circulam e se correlacionam no contexto social, constituindo os sujeitos (Foucault, 2006).

Nessa perspectiva, Tabak (2002) argumenta sobre a necessidade de ações que motivem a inserção das mulheres na ciência, sobretudo em determinados campos da ciência, porém a sociedade brasileira ainda carece de incentivos. Segundo a autora, em geral, as mulheres que ingressam na universidade em cursos tradicionalmente masculinos não recebem durante os anos de graduação estímulos para realizar pesquisas, necessitando ainda conviver num ambiente hostil à sua identidade de gênero. Além disso, preconceitos, casamento, gravidez, filhos, competitividade, falta de incentivos e oportunidades são fatores que contribuem para o desestímulo da mulher na carreira científica. Para a autora, é fundamental modificar os currículos da Educação Básica e da universidade, principalmente os métodos pedagógicos, de modo a estimular as mulheres a integrarem o campo da ciência.

Para finalizar, defendemos a importância de desenvolver pesquisas na perspectiva de gênero na ciência, pois conhecer e visibilizar a história de mulheres no mundo da ciência pode possibilitar a efetiva inserção e participação das mulheres nesse contexto, configurando-se como uma estratégia fundamental para a minimização das desigualdades que caracterizam a sociedade brasileira. 


\section{Referências}

ARROYO, Miguel G. Ciclos de Desenvolvimento Humano e Formação de Educadores. Educação \& Sociedade, Campinas, v. 20, n. 68, p. 143-169, dez. 1999. Disponível em: <http://dx.doi.org/10.1590/ S0101-73301999000300008>. Acesso em: 10 out. 2011.

BELTRÃO, Kaizô Iwakami; ALVES, José Eustáquio Diniz. A reversão do hiato de gênero na educação brasileira no século XX. Cadernos de Pesquisa, v. 39, n. 136, p. 125-156, jan./abr. 2009.

BRASIL. Conselho Nacional de Desenvolvimento Científico e Tecnológico (CNPq). Diretório de Grupos de Pesquisa no Brasil, Plano Tabular. Disponível em: <http://dgp.cnpq.br/planotabular/>. Acesso em: 10 jan. 2012.

BRENES, Anayansi Correa. História da parturição no Brasil, século XIX. Cadernos de Saúde Pública, v. 7, n. 2, p. 135-149, abr./jun. 1991.

BUJES, Maria Isabel. Criança e brinquedo: feitos um para o outro? In: COSTA, Marisa Vorraber (Org.). Estudos Culturais em educação: mídia, arquitetura, brinquedo, biologia, literatura, cinema... Porto Alegre: Ed. Universidade/UFRGS, 2000. p. 205-228.

CONNELLY, Michael e CLANDININ, Jean. Relatos de experiencia e investigación narrativa. In: LARROSA, Jorge et al. Déjame que te cuente. Barcelona: Laertes, 1995.

CORAZZA, Sandra Mara. Por que somos tão tristes? Revista Pátio, Ano VIII, n. 30, p. 51-53, mai/jul. 2004. FELíCIO, José Roberto Drugowich de. Conselho Nacional de Desenvolvimento Científico e Tecnológico. Pensando gênero e ciência. Encontro Nacional de Núcleos e Grupos de Pesquisa - 2009, 2010/ Presidência da República. - Brasília: Secretaria Especial de Políticas para as Mulheres, 2010, p. 45-52.

FOUCAULT, Michel. A ordem do discurso. 11. ed. São Paulo: Loyola, 2004.

Microfísica do poder. 22. ed. Rio de Janeiro: Graal. 2006.

GALIAZZI, Maria do Carmo et al. Objetivos das atividades experimentais no ensino médio: a pesquisa coletiva como modo de formação de professores de ciências. Ciência \& Educação, v. 7, n. 2, p. 249263. 2001.

GUIMARÃES, Valter Soares. Formação de professores: saberes, identidade e profissão. 3. ed. Campinas/SP: Papirus, 2006.

HALL, Stuart. A identidade cultural na pós-modernidade. 10. ed. Rio de Janeiro: DP\&A, 2005.

HARAWAY, Donna. Saberes localizados: a questão da ciência para o feminismo e o privilégio da perspectiva parcial. Cadernos Pagu. Campinas, n. 5, p. 7-41. 1995.

HARDING, Sandra. A instabilidade das categorias analíticas na teoria feminista. Estudos Feministas, n. 1, p. 7-32. 1993.

HENNING, Paula Corrêa. Efeitos de sentido em discursos educacionais contemporâneos: produção de saber e moral nas Ciências Humanas. 2008. 282 f. Tese (Doutorado em Educação) - Programa de Pós-Graduação em Educação, Universidade do Vale do Rio dos Sinos, São Leopoldo, 2008.

KRASILCHIK, Myriam. O professor e o currículo das ciências. 4. ed. São Paulo: EPU, 2006.

LARROSA, Jorge. Narrativa, identidad y desidentificación. In: . La experiencia de la lectura. Barcelona: Laertes, 1996. p. 461-482. 
- Tecnologias do eu e educação. In: SILVA, Tomaz Tadeu da. (Org.) O sujeito da educação: estudos foucaultianos. 5. ed. Petrópolis/RJ: Vozes, 2002.

. Notas sobre narrativa e identidad. In: Abrahão, Maria Helena M. Barreto (Org.). A aventura (auto)biográfica: teoria e empiria. Porto Alegre: EDIPUCRS, 2004. p. 11-22.

SCHIEBINGER, Londa. O feminismo mudou a ciência 2001?São Paulo: EDUSC, 2001.

SILVA, Tomaz Tadeu da. Currículo e identidade social: territórios contestados. In: . (Org.).

Alienígenas na sala de aula: uma introdução aos estudos culturais em educação. 6. ed. Petrópolis/RJ: Vozes, 2005. p. 190-207.

TABAK, Fanny. O laboratório de Pandora: estudos sobre a ciência no feminino. Rio de Janeiro: Garamond, 2002.

TOSI, Lucia. Mulher e Ciência: a revolução científica, a caça às bruxas e a ciência moderna. Cadernos Pagu. Campinas, n. 10, p. 369-397, 1998.

VELHO, Léa; LEÓN, Elena. A construção social da produção científica por mulheres. Cadernos Pagu. Campinas, v. 10, p. 309-344, 1998.

WOODWARD, Kathryn. Identidade e diferença: uma introdução teórica e conceitual. In: SILVA, Tomaz Tadeu da. (Org.). Identidade e diferença: a perspectiva dos Estudos Culturais. 4. ed. Petrópolis/RJ: Vozes, 2005. p. 7-72.

WORTMANN, Maria Lúcia Castagna; VEIGA-NETO, Alfredo. Estudos culturais da ciência \& educação. Belo Horizonte: Autêntica, 2001.

Recebido em outubro de 2011.

Aprovado em janeiro de 2012.

Fabiane Ferreira da Silva, doutoranda em Educação em Ciências na Universidade Federal do Rio Grande - FURG. Professora Assistente da Universidade Federal do Pampa, UNIPAMPA, Campus Uruguaiana. Atua na área de Educação em Ciências e Estudos Feministas. Publicações recentes: Eu não suporto isso: mulher com mulher e homem com homem: analisando as narrativas de adolescentes sobre homofobia (Currículo sem Fronteiras, v. 11, p. 252-280, 2011); Corpos, gêneros, sexualidades e relações étnico-raciais na educação (co-organização com Mello, Elena Maria Billig [Orgs.]. Uruguaiana: UNIPAMPA, 2011, 182p.). E-mail: fabiquimica23ayahoo.com.br.

Paula Regina Costa Ribeiro, doutora em Ciências Biológicas pela Universidade Federal do Rio Grande do Sul. Professora Associada II do Instituto de Educação e dos Programas de Pós-Graduação em Educação Ambiental e Educação em Ciências da Universidade Federal do Rio Grande - FURG. Bolsista de Produtividade em Pesquisa do CNPq. Publicações recentes: Dossiê: Gênero e sexualidade no espaço escolar (co-organização SILVA, Cristiani Bereta da. Revista Estudos Feministas, v. 19, n. 2, 2011); Educação para a sexualidade: uma questão transversal ou disciplinar no currículo escolar? (co-autoria com BARROS, Conceição. Enseñanza de las Ciencias, v. 11, p. 164-187, 2012). E-mail: pribeirodvetorial.net. 